\title{
Outcomes and mortality associated with atrial arrhythmias among patients hospitalized with COVID-19: A systematic review and meta-analysis
}

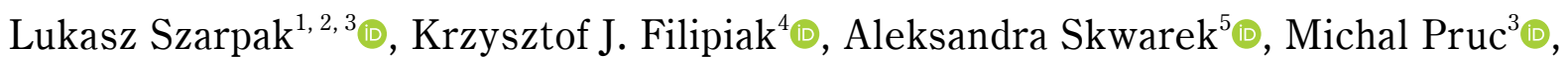 \\ Mansur Rahnama ${ }^{6}{ }^{\oplus}$, Andrea Denegri $^{7}$, Marta Jachowicz ${ }^{8}$, Malgorzata Dawidowska ${ }^{1}$,

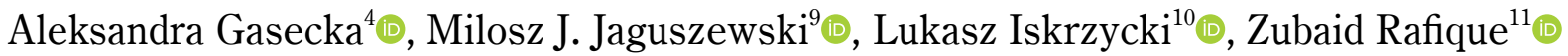 \\ ${ }^{1}$ Institute of Outcomes Research, Maria Sklodowska-Curie Medical Academy, Warsaw, Poland; ${ }^{2}$ Research \\ Unit, Maria Sklodowska-Curie Bialystok Oncology Center, Bialystok, Poland; ${ }^{3}$ Research Unit, Polish \\ Society of Disaster Medicine, Warsaw, Poland; ${ }^{4}$ Institute of Clinical Medicine, Maria Sklodowska-Curie \\ Medical Academy, Warsaw, Poland; ${ }^{5} 1^{\text {st }}$ Chair and Department of Cardiology, Medical University of Warsaw, \\ Warsaw, Poland; ${ }^{6}$ Chair and Department of Oral Surgery, Medical University of Lublin, Poland; ${ }^{7}$ Cardiology \\ Division, Department of Biomedical, Metabolic and Neural Sciences, University of Modena and Reggio \\ Emilia, Policlinico di Modena, Modena, Italy; ${ }^{8}$ Students Research Club, Maria Sklodowska-Curie Medical \\ Academy, Warsaw, Poland; ${ }^{9} 1^{\text {st }}$ Department of Cardiology, Medical University of Gdansk, Poland; \\ ${ }^{10}$ Department of Emergency Medical Service, Medical University of Wroclaw, Poland; ${ }^{11}$ Henry JN Taub \\ Department of Emergency Medicine, Baylor College of Medicine, Houston, TX, United States
}

\section{This paper was guest edited by Prof. Togay Evrin}

\begin{abstract}
Background: Atrial fibrillation $(A F)$ is the most common cardiac arrhythmia in the adult population. Herein, is a systematic review with meta-analysis to determine the impact of AF/atrial futter (AFL) on mortality, as well as individual complications in patients hospitalized with the coronavirus disease 2019 (COVID-19).

Methods: A systematic search of the SCOPUS, Medline, Web of Science, CINAHL and Cochrane databases was performed. The a priori primary outcome of interest was in-hospital mortality. A random-effects model was used to pool study results.

Results: Nineteen studies which included 33,296 patients were involved in this meta-analysis. Inhospital mortality for $A F / A F L$ vs. no-AF/AFL groups varied and amounted to $32.8 \%$ vs. $14.2 \%$, respectively (risk ratio [RR]: 2.18; 95\% confidence interval [CI]: 1.79-2.65; $p<0.001$ ). In-hospital mortality in new onset $A F / A F L$ compared to no-AFAFL was $22.0 \%$ vs. $18.8 \%$ (RR: 1.86; 95\% CI: 1.54-2.24; $p<0.001$ ). Intensive care unit (ICU) admission was required for $17.7 \%$ of patients with $A F / A F L$ compared to $10.8 \%$ for patients without $A F / A F L$ (RR: 1.94; 95\% CI: 1.04-3.62; $p=0.04$ ).

Conclusions: The present study reveals that $A F / A F L$ is associated with increased in-hospital mortality and worse outcomes in patients with COVID-19 and may be used as a negative prognostic factor in these patients. Patients with AF/AFL are at higher risk of hospitalization in ICU. The presence of AF/AFL in individuals with COVID-19 is associated with higher risk of complications, such as bleeding, acute kidney injury and heart failure. AF/AFL may be associated with unfavorable outcomes due to the hemodynamic compromise of cardiac function itself or hyperinflammatory state typical of these conditions. (Cardiol J 2022; 29, 1: 33-43)
\end{abstract}

Key words: atrial fibrillation, atrial flutter, new onset atrial fibrillation, COVID-19, outcome, systematic review, meta-analysis

Address for correspondence: Lukasz Szarpak, Assoc. Prof. PhD, DPH, DBA, MBA, Institute of Outcomes Research, Maria Sklodowska-Curie Medical Academy, Lubomirski Palace, ul. Żelazna Brama 10, 00-136 Warszawa, Poland, tel: +48 500-186-225, e-mail: lukasz.szarpak@gmail.com

Received: 9.11.2021 Accepted: 27.11.2021 Early publication date: 9.12.2021

This article is available in open access under Creative Common Attribution-Non-Commercial-No Derivatives 4.0 International (CC BY-NC-ND 4.0) license, allowing to download articles and share them with others as long as they credit the authors and the publisher, but without permission to change them in any way or use them commercially. 


\section{Introduction}

Cardiovascular diseases (CVD) are known to affect the prognosis of patients hospitalized with coronavirus disease 2019 (COVID-19) caused by severe acute respiratory syndrome coronavirus type 2 (SARS-CoV-2) [1, 2]. It has been demonstrated that patients with pre-existing comorbidities, e.g., hypertension, coronary artery disease (CAD) or congestive heart failure are more likely to suffer from the severe course of COVID-19 [3, 4], more often require admission to the intensive care unit (ICU) [4-6], use mechanical ventilation [3, 7] and have higher mortality $[3,7,8]$, compared to patients without CVD. This is a sign of increased vulnerability towards the virus and subsequent disease.

Atrial fibrillation (AF) is the most common cardiac arrhythmia in the adult population. According to European Society of Cardiology, global prevalence of AF oscillates between $2 \%$ and $4 \%$ and is expected to further increase due to longevity, including an expanding group of people with long-lasting underlying CVD [9]. The incidence of atrial flutter (AFL) in individuals without recent predisposing events and preexisting comorbidities is estimated to reach $1.7 \%$ [10]. Pathophysiological mechanisms responsible for those arrhythmias include i.e.: structural and electrical atrial remodeling through fibrosis, hypertrophy, inflammation or oxidative stress $[9,11,12]$. Acute inflammation in the course of COVID-19 may alter atrial electrophysiology and structural substrates, therefore playing a major role in the development of these conditions in patients with COVID-19 [13]. Due to the well-established links between inflammation and AF, the association between COVID-19 and $\mathrm{AF}$ constitutes an interesting and thus far, unexplored subject.

Outcome analysis of patients hospitalized with COVID-19 provides valuable data that can generate new hypotheses regarding the pathophysiology of $\mathrm{AF}$ and AFL, help to identify patients at a higher risk for adverse outcomes and improve patient management within hospital wards. Previously published literature on the outcomes of COVID-19 patients with AF/AFL consists mainly of retrospective studies, rarely single-center prospective ones and very often provides conflicting results. This problem has previously been addressed in the "discussion forum" section of European Heart Journal $[14,15]$ or in review articles [16].

However, to reach solid conclusions regarding the association between AF/AFL and outcomes of patients with COVID-19, a systematic analysis of available data is indispensable. The available research is insufficient, with one meta-analysis published in January 2021, providing data about the influence of AF on outcomes of patients with COVID-19 [17]. However, it only evaluated the mortality outcomes, without considering other complications, and it has been limited to the European and United States populations. Furthermore, due to the constant changes in our understanding of COVID-19, development of new treatment protocols and pandemic dynamics itself, it is essential to provide updated, high-quality data regarding the association between COVID-19 and CVD. A systematic review with meta-analysis was performed herein, to determine the impact of $\mathrm{AF} / \mathrm{AFL}$ on mortality, as well as individual complications in patients hospitalized with COVID-19.

\section{Methods}

The current systematic review and metaanalysis was complied with the widely recognized Preferred Reporting Items for Systematic Reviews and Meta-Analyses (PRISMA) statement (Suppl. Table S2) [18]. Due to the study design, neither an institutional review board approval nor patient informed consent were required.

\section{Search strategy}

An extensive search was conducted of the relevant data using the SCOPUS, Medline, Web of Science, CINAHL and the Cochrane Central Register for Controlled Trials from these databases inception through to October $10^{\text {th }}, 2021$. The search was performed using the following terms: "atrial fibrillation" OR "AF" OR "atrial flutter" OR "AFL" AND “COVID-19" OR “coronavirus disease 2019" OR "SARS-CoV-2". Two of the reviewers (M.P. and A.G.) independently selected candidates for the study, and conflicts were resolved through discussion with a third reviewer (L.S.).

Studies comparing adult COVID-19 patients more than 18 years old with and without AF/AFL were systematically searched as noted. All randomized controlled trials (RCTs) and observational studies were included in this review. Case reports, case series, and conference abstracts were excluded.

\section{Data extraction}

Two reviewers (L.S. and M.P.) independently assessed each article to determine whether they met the inclusion criteria. In cases of suspected 
data discrepancies, the relevant author was contacted directly, moreover, care was taken to avoid including data from duplicate publications.

\section{Primary and secondary outcomes}

The a priori primary outcome of interest was in-hospital mortality. Secondary outcomes were: occurrence of adverse events, in-hospital cardiovascular death or hospital- or ICU-length of stay.

\section{Risk of bias assessment}

Risk Of Bias In Non-randomized Studies was used - the Interventions (ROBINS-I) tool was utilized to assess the quality of the studies' design and extent of potential bias [19]. The ROBINS-I tool examines five bias domains: (1) bias due to confounding; (2) bias due to selection of participants; (3) bias in classification of interventions; (4) bias due to deviations from intended interventions; (5) bias due to missing data; (6) bias in measurement of outcomes; (7) bias in selection of the reported result. The overall ROBINS-I judgment at domain and study level was attributed according to the criteria specified in the ROBVIS tool [20].

\section{Statistical analysis}

The Cochrane Statistical Package Review Manager ver. 5.4 (Cochrane Collaboration, London, United Kingdom) was used for data synthesis and analysis. For dichotomous data, odds ratios (ORs) or risk ratios (RRs) as the effect measure were used with $95 \%$ confidence intervals (CIs), and for continuous data, standard mean differences (SMDs) with 95\% CI were used. In cases where the continuous outcome was reported in a study as median, range, and interquartile range, means and standard deviations were estimated using the formula described by Hozo et al. [21]. Heterogeneity was quantified in each analysis by the tau-squared and $\mathrm{I}^{2}$ statistics. Values of $\mathrm{I}^{2}>50 \%$ and $>75 \%$ were considered to indicate moderate and significant heterogeneity among studies, respectively. A random-effects model was used to pool study results independently of the p-value for heterogeneity or $\mathrm{I}^{2}$ [22].

\section{Results}

\section{Characteristics of studies included in the meta-analysis}

A total of 1,012 articles were identified from the Medline (PubMed), Embase, Cochrane library, and the manual search as described above. Ultimately, 19 studies [23-41] published from 2020 to
2021 which included 33,296 patients in the metaanalysis (Fig. 1). The details of the selected trials are summarized in Table 1.

Male gender in the AF/AFL and no-AF/AFL groups varied and amounted to $56.6 \%$ vs. $52.4 \%$ (OR: 1.23; 95\% CI: 1.05-1.44; I': 64\%; p = 0.01). Mean age of patients in AF/AFL group was $73.8 \pm$ \pm 11.2 years compared to $61.8 \pm 17.5$ years for no AF/AFL group (SMD: 0.90; 95\% CI: 0.39-1.41; I': $99 \% ; \mathrm{p}<0.001)$. Detailed characteristics of patient comorbidities are presented in the Supplementary Table S1.

\section{Results of the meta-analysis}

In-hospital mortality was reported in 18 studies and was $32.8 \%$ for AF/AFL group compared to $14.2 \%$ (RR: 2.18; 95\% CI: 1.79-2.65; I²: 90\%; p < 0.001; Fig. 2). Sub-analysis showed that in-hospital mortality in new onset AF/AFL compared to the non-AF/AFL group amounted to $22.0 \%$ vs. $18.8 \%$ (RR: 1.86; 95\% CI: 1.54-2.24; I²: 72\%; p < 0.001; Fig. 3).

In-hospital cardiovascular death was reported in 1 study [40] and was $10.4 \%$ vs. $5.2 \%$ respectively for patients with and without AF/AFL (RR: 2.02; 95\% CI: 1.11-3.66; $\mathrm{p}=0.02$ ). Uribarri et al. [41] also showed 60 -day mortality which was $43.3 \%$ vs. $30.9 \%$, respectively (RR: 1.40 ; $95 \%$ CI: $1.10-1.79$; $\mathrm{p}=0.02)$.

Intensive care unit admission was required for $17.7 \%$ of patients with $\mathrm{AF} / \mathrm{AFL}$ compared to $10.8 \%$ for patients without AF/AFL (RR: 1.94; 95\% CI: $1.04-3.62 ; \mathrm{I}^{2}: 72 \%$; $\left.\mathrm{p}=0.04\right)$.

Mechanical ventilation was reported in 6 studies and was $14.4 \%$ vs. $5.2 \%$ for patients with and without AF/AFL (RR: 1.76; 95\% CI: 0.92-3.36; I²: $89 \% ; \mathrm{p}=0.09)$.

A pooled analysis of the observed adverse events is presented in Table 2. Patients with AF/ /AFL had a higher risk of bleeding events $(9.1 \%$ vs. $3.2 \%$; RR: $3.50 ; 95 \%$ CI: $1.55-7.91 ; I^{2}: 47 \%$; $\mathrm{p}=0.003)$, heart failure (HF) $(23.1 \%$ vs. $18.2 \%$; RR: 1.39; 95\% CI: $1.01-1.91 ; \mathrm{I}^{2}: 35 \%$; $\left.=0.04\right)$ as well as higher risk of acute kidney injury (AKI) (41.9\% vs. $40.1 \%$; RR: 1.31 ; $95 \%$ CI: $1.10-1.57$; I : $0 \%$; $\mathrm{p}=0.003$ ), compared to patients without AF/AFL.

Length of stay in ICU was reported in 2 studies and was $10.2 \pm 21.9$ days for $\mathrm{AF} / \mathrm{AFL}$ group compared to $37.9 \pm 18.7$ days for no AF/AFL group (SMD: -1.40 ; $95 \%$ CI: -5.54 to $2.75 ; \mathrm{I}^{2}$ : $100 \%$; $\mathrm{p}=0.51$; Fig. 4 ).

Hospital length of stay in AF/AFL and no AF/ /AFL amounted to $9.4 \pm 3.7$ vs. $8.0 \pm 3.1$ days, respectively (SMD: 1.27; 95\% CI: 0.18-2.36; I': 99\%; $\mathrm{p}=0.02)$. 


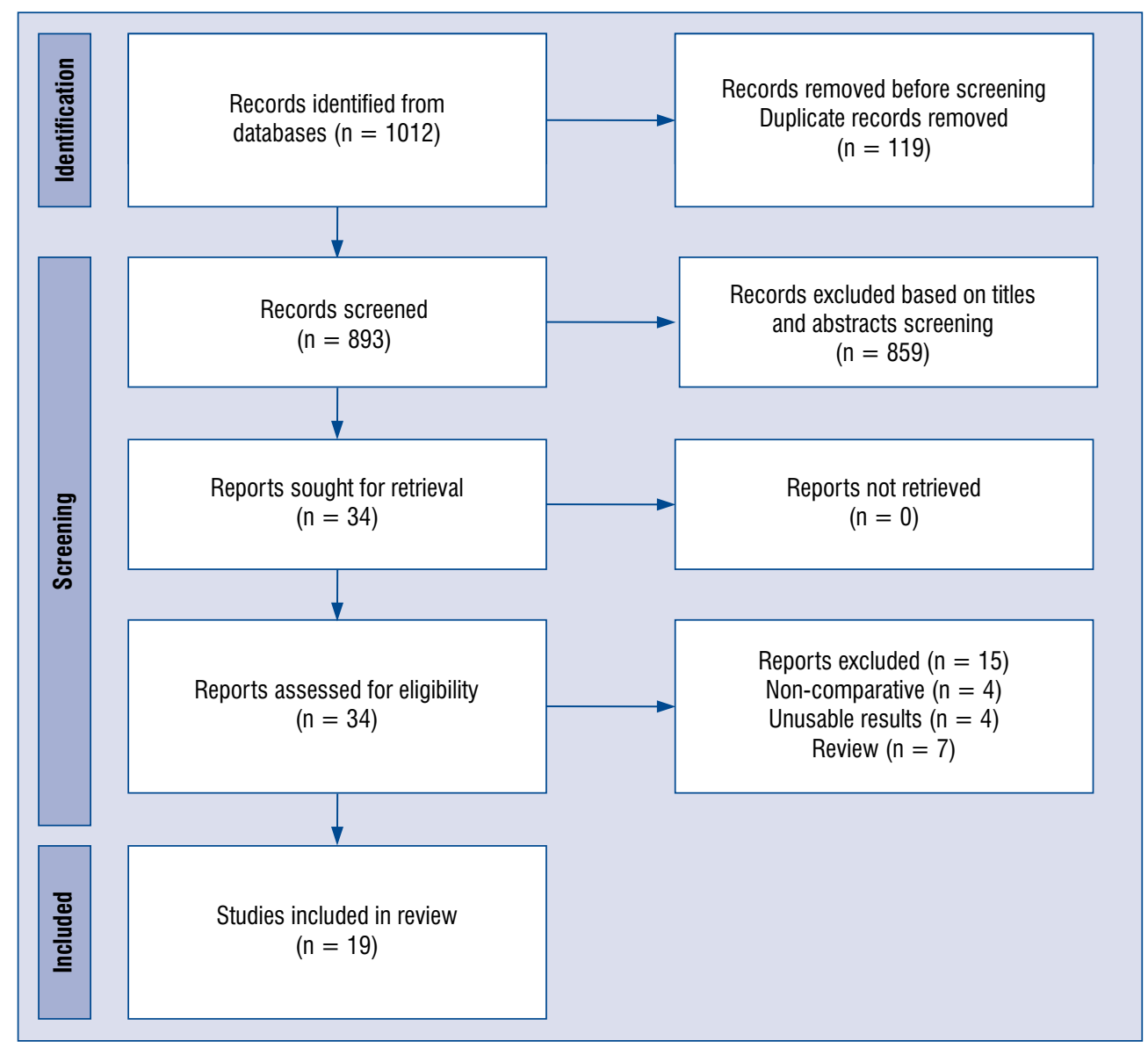

Figure 1. Flow diagram showing stages of the database search and study selection as per Preferred Reporting Items for Systematic Reviews and Meta-Analyses (PRISMA) guidelines.

\section{Discussion}

General considerations and study population

Cardiovascular diseases, such as hypertension, have already been shown to worsen the prognosis of COVID-19 patients, both in terms of morbidity (increased risk of developing severe disease, need for hospitalization within ICU) and mortality [4, 8]. However, so far, no consensus has been reached regarding the impact of $\mathrm{AF}$ on the outcome of patients with COVID-19.

Atrial fibrillation and flutter are arrhythmias occurring mostly in the elderly, with hypertensive heart disease and coronary heart disease being the most frequently observed underlying disorders. According to previous studies, at least one risk factor, most often hypertension, is present among COVID-19 patients developing AF [42, 43]. However, there are also reports regarding new-onset $\mathrm{AF}$ emerging without any pre-existing illness $[42,44,45]$. The most prevalent comorbidities in patients with $\mathrm{AF} / \mathrm{AFL}$ in this study included hypertension, chronic obstructive pulmonary disease (COPD) and CAD. Furthermore, the groups with $\mathrm{AF} / \mathrm{AFL}$ tend to be of older age compared to groups without $\mathrm{AF} / \mathrm{AFL}$, with the difference in the mean age reaching as high as 24.6 years in one study [32].

\section{Mortality in new-onset}

vs. pre-existing AF/AFL

Based on our findings, mortality was 2.18 -fold higher in COVID-19 patients with pre-existing $\mathrm{AF} / \mathrm{AFL}$, compared to the non-AF/AFL group. This increase is much higher, compared to the previous meta-analysis, where the mortality was only 1.13-fold higher in patients with AF [17]. The reason for this difference, may be the inclusion of different populations in the present study, since the previous meta-analysis took into consideration only studies conducted in Europe and the United States. The magnitude of the increased risk in patients with pre-existing AF hospitalized due to COVID-19, remains to be established. 


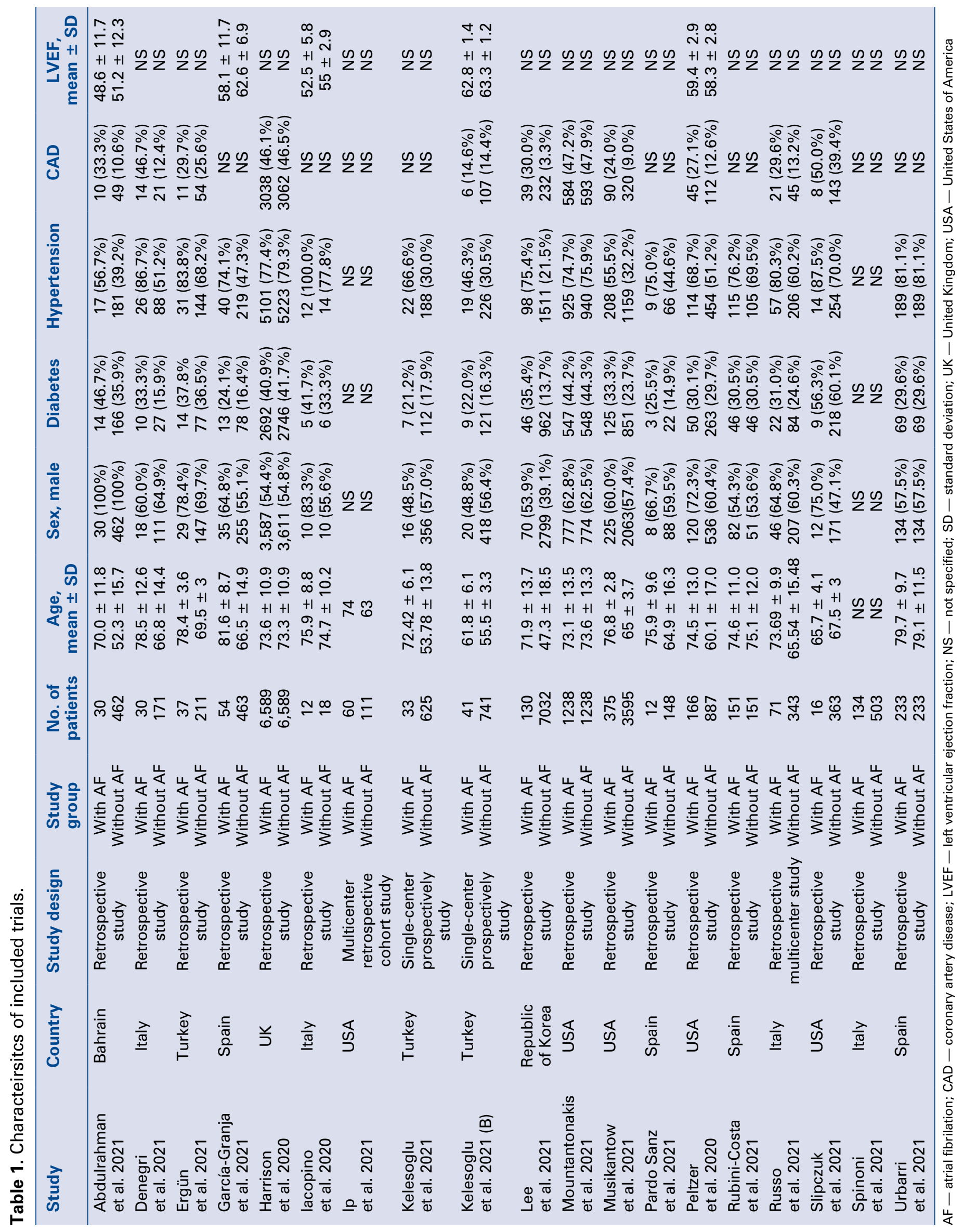




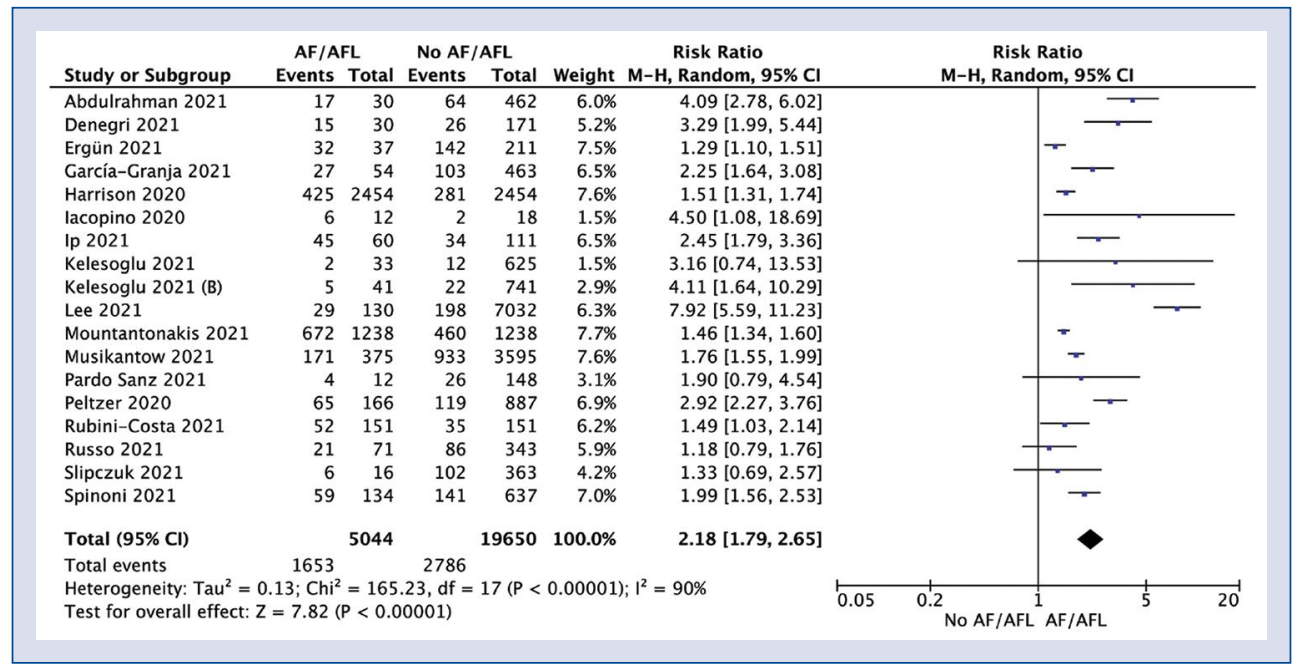

Figure 2. Forest plot of in-hospital mortality in atrial fibrillation/atrial flutter (AF/AFL) and no-AF/AFL groups. The center of each square represents the weighted risk ratios for individual trials, and the corresponding horizontal line stands for a $95 \%$ confidence interval (Cl). The diamonds represent pooled results.

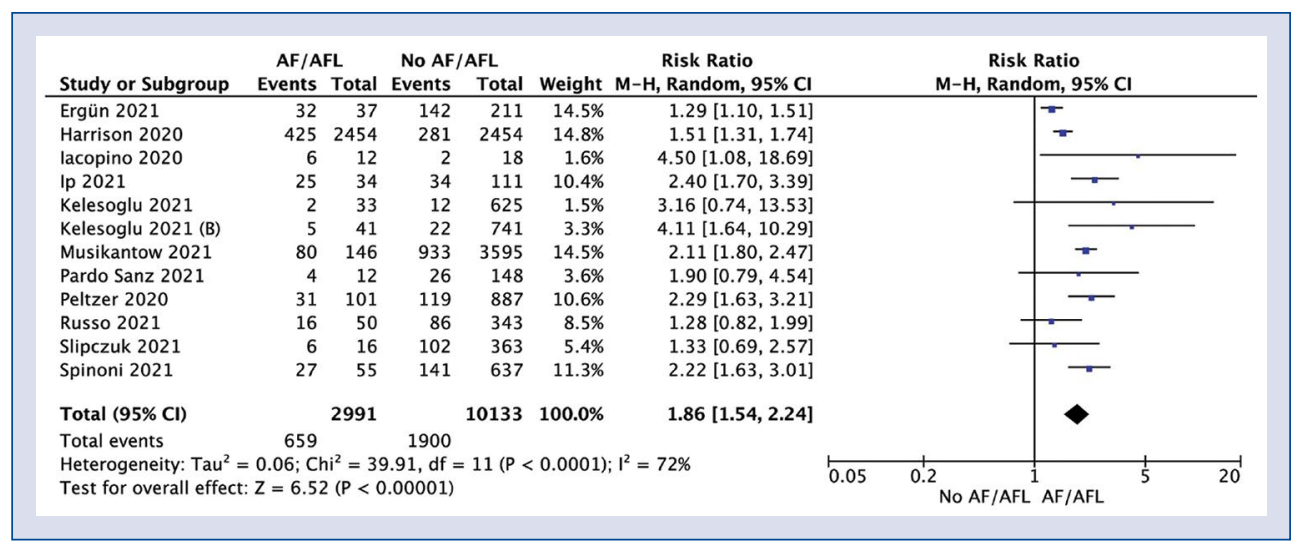

Figure 3. Forest plot of in-hospital mortality in new onset atrial fibrillation/atrial flutter (AF/AFL) no-AF/AFL groups. The center of each square represents the weighted risk ratios for individual trials, and the corresponding horizontal line stands for a $95 \%$ confidence interval $(\mathrm{Cl})$. The diamonds represent pooled results.

Due to a high prevalence of broad spectrum of comorbidities in patients with AF/AFL (e.g., hypertension, COPD, CAD) the distinction needs to be made between the impact of $\mathrm{AF} / \mathrm{AFL}$ and the impact of other chronic diseases on in-hospital mortality. To date, in spite of the burden of comorbidities in patients with AF/AFL, many studies included in this meta-analysis confirmed that AF/AFL is an independent negative prognostic factor in patient with COVID-19 [23, 24, 29, 32, 33, 36, 37, 40, 41]. To confirm this finding, AF was associated with higher in-hospital mortality mainly in patients with a low or intermediate $\mathrm{CHA}_{2} \mathrm{DS}_{2}$-VASc score [15], suggesting that the existence of AF/AFL is not only the cumulative measure of risk due to other chronic diseases, but a novel prognostic factor. Hence, AF/AFL are potentially useful in clinical routine to identify patients at a higher risk of death, suggesting a need for a closer monitoring and a more intensive therapy.

Interestingly, the current study demonstrated that COVID-19 patients with new-onset AF/AFL had a 1.8-fold higher risk of mortality, compared to patients without $\mathrm{AF} / \mathrm{AFL}$, whereas patients with pre-existing AF had 2.18-fold higher risk of mortality, as compared to patients without AF/AFL. This suggests that especially pre-existing AF/AFL exerts its negative effects 
Table 2. Polled analysis of adverse events among included trials.

\begin{tabular}{|c|c|c|c|c|c|c|c|c|}
\hline \multirow[t]{2}{*}{$\begin{array}{l}\text { Adverse } \\
\text { event }\end{array}$} & \multirow[t]{2}{*}{$\begin{array}{l}\text { No. of } \\
\text { studies }\end{array}$} & \multicolumn{2}{|c|}{ Events/participants } & \multicolumn{2}{|c|}{ Events } & \multicolumn{2}{|c|}{$\begin{array}{l}\text { Heterogeneity } \\
\text { between trials }\end{array}$} & \multirow{2}{*}{$\begin{array}{c}\text { P-value for } \\
\text { differences } \\
\text { across } \\
\text { groups }\end{array}$} \\
\hline & & AF/AFL & No AF/AFL & $\mathbf{R R}$ & $95 \% \mathrm{Cl}$ & $\mathrm{P}$-value & I² $^{2}$ tatistic & \\
\hline $\begin{array}{l}\text { Embolic } \\
\text { events }\end{array}$ & 3 & $\begin{array}{c}253 / 2699 \\
(9.4 \%)\end{array}$ & $\begin{array}{c}181 / 2835 \\
(6.4 \%)\end{array}$ & 2.81 & $0.75-10.51$ & 0.001 & $86 \%$ & 0.12 \\
\hline APE & 2 & $\begin{array}{c}3 / 91 \\
(3.3 \%)\end{array}$ & $\begin{array}{l}14 / 674 \\
(2.1 \%)\end{array}$ & 1.80 & $0.10-32.61$ & 0.07 & $70 \%$ & 0.69 \\
\hline Stroke & 2 & $\begin{array}{c}7 / 429 \\
(1.6 \%)\end{array}$ & $\begin{array}{c}34 / 4058 \\
(0.8 \%)\end{array}$ & 1.95 & $0.87-4.37$ & 0.75 & $0 \%$ & 0.11 \\
\hline $\begin{array}{l}\text { Bleeding } \\
\text { events }\end{array}$ & 4 & $\begin{array}{l}41 / 450 \\
(9.1 \%)\end{array}$ & $\begin{array}{l}32 / 995 \\
(3.2 \%)\end{array}$ & 3.50 & $1.55-7.91$ & 0.13 & $47 \%$ & 0.003 \\
\hline Acute MI & 2 & $\begin{array}{c}0 / 91 \\
(0.0 \%)\end{array}$ & $\begin{array}{l}11 / 674 \\
(1.6 \%)\end{array}$ & 0.77 & $0.07-8.87$ & 0.25 & $25 \%$ & 0.84 \\
\hline Heart failure & 3 & $\begin{array}{c}75 / 324 \\
(23.1 \%)\end{array}$ & $\begin{array}{l}165 / 907 \\
(18.2 \%)\end{array}$ & 1.39 & $1.01-1.91$ & 0.22 & $35 \%$ & 0.04 \\
\hline Myocarditis & 2 & $0 / 66(0.0 \%)$ & $1 / 481(0.2 \%)$ & 2.81 & $0.12-68.19$ & NA & NA & 0.53 \\
\hline $\begin{array}{l}\text { Ventricular } \\
\text { arrhythmia }\end{array}$ & 1 & $\begin{array}{c}1 / 54 \\
(1.9 \%)\end{array}$ & $\begin{array}{c}0 / 463 \\
(0.0 \%)\end{array}$ & 25.31 & $1.04-613.72$ & NA & NA & 0.05 \\
\hline CPR & 1 & $1 / 37(2.7 \%)$ & $8 / 211(3.8 \%)$ & 0.71 & $0.09-5.53$ & NA & NA & 0.75 \\
\hline $\begin{array}{l}\text { Acute kidney } \\
\text { injury }\end{array}$ & 2 & $\begin{array}{l}113 / 270 \\
(41.9 \%)\end{array}$ & $\begin{array}{l}178 / 444 \\
(40.1 \%)\end{array}$ & 1.31 & $1.10-1.57$ & 0.66 & $0 \%$ & 0.003 \\
\hline $\mathrm{RRT}$ & 1 & $\begin{array}{c}14 / 37 \\
(37.8 \%)\end{array}$ & $\begin{array}{c}52 / 211 \\
(24.6 \%)\end{array}$ & 1.54 & $0.95-2.47$ & NA & NA & 0.08 \\
\hline
\end{tabular}

$\mathrm{AF}$ - atrial fibrillation; $\mathrm{AFL}$ - atrial flutter; $\mathrm{APE}$ — acute pulmonary embolism; $\mathrm{Cl}$ — confidence interval; $\mathrm{CPR}$ — cardiopulmonary resuscitation; $\mathrm{MI}$ - myocardial infarction; NA — not applicable; RR — risk ratio; RRT — renal replacement therapy

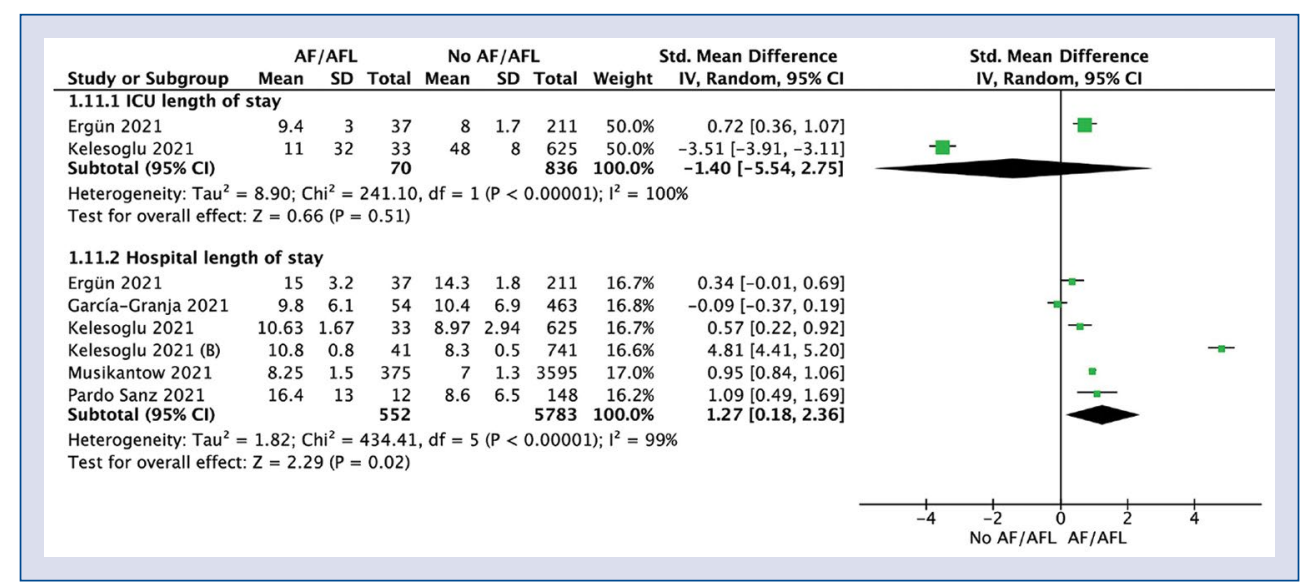

Figure 4. Forest plot of length of hospital stay in atrial fibrillation/atrial flutter (AF/AFL) and no-AF/AFL groups. The center of each square represents the weighted standard mean differences for individual trials, and the corresponding horizontal line stands for a $95 \%$ confidence interval (CI). The diamonds represent pooled results; ICU - intensive care unit.

in the course of COVID-19. The higher risk of mortality in the group with long-lasting $\mathrm{AF} / \mathrm{AFL}$ can also be an indicator of a long-term hemodynamic compromise, caused by the persistent effect of arrhythmia on the effectivity of atrial systole, which may produce higher susceptibility for adverse outcomes.

\section{Mid-term mortality}

One study provided additional data on 60-day mortality, which indicated a slightly lower increase in mortality between the AF/AFL group, compared to the non-AF/AFL group (RR: 1.40) [41]. This may suggest that the highest burden of $\mathrm{AF} / \mathrm{AFL}$ falls on the period 
of first hospitalization, indicating the special need of intensive care and monitoring in the acute phase.

\section{Reasons for increased mortality in AF/AFL}

There are several theories explaining the association of $\mathrm{AF} / \mathrm{AFL}$ with worse outcomes in COVID-19 that are strongly related to the molecular mechanisms underlying the electrical instability of atrial arrhythmias, hyperinflammatory state and mechanical stress on the cardiomyocytes.

Firstly, AF is associated with increased levels of angiotensin-converting enzyme 2 (ACE-2), the enzyme localized on the surface of coronary endothelial cells, cardiomyocytes and cardiac fibroblasts. In AF, levels of ACE-2 correlate strongly with the remodeling of the left atrium and play a pathophysiologic role by creating the substrate for arrhythmia [41, 46]. At the same time, ACE-2 is a receptor for SARS-CoV-2, allowing for viral entry. Higher levels of ACE-2 are associated with higher susceptibility for infections with SARSCoV-2 and developing COVID-19 by allowing for a higher viral load within cells [46]. AF may be associated with higher levels of ACE-2, responsible for unfavorable outcomes. On the other hand, ACE-2 may also play a direct role in the cardiac involvement in the course of COVID-19. ACE-2 receptors are present on the cardiomyocytes as well pericytes in the vessels of microvasculature of the heart. Pericytes envelope the endothelial cells of microcirculation, providing vascular integrity [47-49]. It has been speculated that SARS-CoV-2 may interact with ACE-2 receptors on pericytes and lead to vascular leakage and consequent myocardial edema [11]. The edema, in turn, through increased interstitial hydrostatic pressure may lead to aberrations in ion channels conductance, predisposing patients with cardiac complications to AF. Consequently, a new-onset AF may be a manifestation of AKI.

Secondly, an inflammatory state underlies and predicts the onset of AF in humans [41]. An increasing body of evidence demonstrates the role of inflammatory markers (e.g., interleukin- 6 and tumor necrosis factor alpha) [50-52], as well as inflammatory infiltrates within the myocardium in pathophysiology of AF [12, 53, 54]. Conversely, persistent AF itself favors remodeling by promoting inflammation, perpetuating the aberrations on the level of electrical conductance and producing the so-called 'AF begets AF' phenomenon. Consequently, individuals with long-lasting AF may be at higher risk of developing a hyperinflammatory reaction in the course of COVID-19 but also in patients undergoing COVID-19, developing a hyperinflammatory state, and are more likely to suffer from new-onset AF.

Thirdly, some studies suggest that AF may be the consequence of pulmonary vascular dysfunction (PVD), a condition frequently underlying acute respiratory distress syndrome. In this scenario, PVD is characterized by enhanced inflammatory signaling, remodeling and thrombosis within the microvasculature of the lungs, exerts mechanical stress on the right atrium and consequently on structural and electrical changes in cardiomyocytes. This creates a substrate for arrhythmias, especially AF. Studies conducted before the pandemic supported this hypothesis, showing a higher prevalence of $\mathrm{AF}$ in patients with pulmonary hypertension and tachycardia, both of which frequently occur in the course of COVID-19 [55]. In this regard, a new-onset $\mathrm{AF}$ would be a condition reflecting the occurrence of $\mathrm{PVD}$.

Elucidating the exact cause or mechanism of death in individuals remains a challenge. This study demonstrated that in-hospital cardiovascular death occurred 2 times more often in the AF/AFL group compared to the non-AF/AFL group. These results are, however, based solely on one retrospective study, hence, does not allow drawing general conclusions. Therefore, we suggest that future studies should make the distinction between cardiovascular death, and non-cardiovascular causes. Also, due to the significance of inflammation in the pathophysiology of $\mathrm{AF} / \mathrm{AFL}$, we recommend measuring inflammatory parameters and correlating them with adverse outcomes.

\section{ICU admission}

The present study has demonstrated that ICU admission was required more frequently in the $\mathrm{AF} /$ /AFL group compared to the non-AF/AFL group, although no significant difference in the ICU length of stay was observed. Further analysis of 2 studies $[25,30]$ provided insights regarding the mechanisms in which AF/AFL may contribute to worse outcomes in the examined group of patients. In the study of Ergün et al. [25], conducted with a group of ICU-patients, the laboratory findings showed an evident increase in the markers of cardiac injury (e.g., high sensitive troponin I; B-type natriuretic peptide) in the group with new-onset atrial fibrillation (NOAF) compared to the group without NOAF. Interestingly, no such difference was visible for C-reactive protein, white blood cell count, lymphocytes or neutrophils. In another study by Uribarri et al. [41] patients with AF have a significantly higher incidence of $\mathrm{HF}$, but lower incidence of respiratory insufficiency, high 
flow nasal cannula, both with noninvasive and invasive mechanical ventilation.

This suggests that AF/AFL may exert its detrimental effects (reflected by the necessity of therapy in ICU) through myocardial injury rather than only passively reflecting the lung pathology and hyperinflammatory state. These findings may be relevant for the therapy of COVID-19 patients, as the scenario where AF/AFL causes worse outcomes directly through cardiac injury that requires different specific therapy administered by a team with extensive cardiological knowledge, as compared to the scenario, where AF/AFL merely accompanies severe disease where the stress is put on anesthesiologic therapy.

\section{Individual complications}

The complications occur significantly more frequently in COVID-19 patients with AF/AFL, compared to those without AF/AFL including bleeding events, AKI and HF.

Bleeding complications occurred 3.5 times more often in the AF/AFL group compared to the non-AF/AFL group, based on 4 studies [26, 35, $37,41]$. Interestingly, 1 study reported that in patients with $\mathrm{AF}$, a percentage of those treated with appropriate doses of anticoagulants was low (57\%) [41]. The remaining individuals were either treated with a prophylactic dose only $(25.7 \%)$ or did not receive any anticoagulant treatment (17.3\%). In spite of that, the incidence of relevant bleeding complications in the $\mathrm{AF}$ group was more than 4 times higher compared to the non-AF group (OR: 4.03). The study by Rubini-Costa et al. [37] demonstrated no statistical association between any anticoagulant medication and the risk of major bleeding. Consequently, anticoagulants seem to be not the main factor responsible for bleeding and further research is warranted to investigate the pathophysiology behind bleeding complications.

The present study found that AKI is 1.31 higher in the patients with AF/AFL, as compared with patients without AF/AFL. In the study by Ergün et al. [25] in the NOAF group, compared with non-NOAF group, the incidence of secondary bacterial infections was higher $(75.7 \%$ vs. $51.7 \%)$ and comparable to the frequency of AKI, suggesting that there may be links between these 2 phenomena and NOAF [25]. In fact, AF was described as the most common arrhythmia in patients with sepsis [56] and the one associated with increased mortality in this group [57], which demonstrates its links with the acute inflammatory state.

\section{Conclusions}

The present study showed that AF/AFL is associated with increased in-hospital mortality and worse outcomes in patients with COVID-19 and may be used as a negative prognostic factor in these patients. Patients with $\mathrm{AF} / \mathrm{AFL}$ are at higher risk of hospitalization in ICU. The presence of $\mathrm{AF} /$ /AFL in individuals with COVID-19 is associated with higher risk of complications, such as bleeding, AKI and HF. AF/AFL may be associated with unfavorable outcomes due to the hemodynamic compromise of cardiac function itself or hyperinflammatory state typical of these conditions.

\section{Acknowledgments}

The study was supported by the Polish Society of Disaster Medicine.

\section{Conflict of interest: None declared}

\section{References}

1. Dzieciatkowski T, Szarpak L, Filipiak KJ, et al. COVID-19 challenge for modern medicine. Cardiol J. 2020; 27(2): 175-183, doi: 10.5603/CJ.a2020.0055, indexed in Pubmed: 32286679.

2. Ruetzler K, Szarpak L, Filipiak K, et al. The COVID-19 pandemic - a view of the current state of the problem. Dis Emerg Med J. 2020, doi: 10.5603/demj.a2020.0015.

3. Bhatt AS, Jering KS, Vaduganathan M, et al. Clinical outcomes in patients with heart failure hospitalized with COVID-19. JACC Heart Fail. 2021; 9(1): 65-73, doi: 10.1016/j.jchf.2020.11.003, indexed in Pubmed: 33384064.

4. Li Bo, Yang J, Zhao F, et al. Prevalence and impact of cardiovascular metabolic diseases on COVID-19 in China. Clin Res Cardiol. 2020; 109(5): 531-538, doi: 10.1007/s00392-020-01626-9, indexed in Pubmed: 32161990.

5. Huang C, Wang Y, Li X, et al. Clinical features of patients infected with 2019 novel coronavirus in Wuhan, China. Lancet. 2020; 395(10223): 497-506, doi: 10.1016/s0140-6736(20)30183-5.

6. Wang $\mathrm{D}, \mathrm{Hu} \mathrm{Bo}, \mathrm{Hu}$ C, et al. Clinical characteristics of 138 hospitalized patients with 2019 novel coronavirus-infected pneumonia in Wuhan, China. JAMA. 2020; 323(11): 1061-1069, doi: 10.1001/ jama.2020.1585, indexed in Pubmed: 32031570.

7. Chan JWM, Ng CK, Chan YH, et al. Short term outcome and risk factors for adverse clinical outcomes in adults with severe acute respiratory syndrome (SARS). Thorax. 2003; 58(8): 686-689, doi: 10.1136/thorax.58.8.686, indexed in Pubmed: 12885985.

8. Wu Z, McGoogan JM. Characteristics of and Important Lessons From the Coronavirus Disease 2019 (COVID-19) Outbreak in China: Summary of a Report of 72314 Cases From the Chinese Center for Disease Control and Prevention. JAMA. 2020; 323(13): 1239-1242, doi: 10.1001/jama.2020.2648, indexed in Pubmed: 32091533.

9. Hindricks G, Potpara T, Dagres N, et al. 2020 ESC Guidelines for the diagnosis and management of atrial fibrillation developed in collaboration with the European Association for Cardio-Thoracic Surgery (EACTS): The Task Force for the diagnosis and management of atrial fibrillation of the European Society of Cardiology 
(ESC) Developed with the special contribution of the European Heart Rhythm Association (EHRA) of the ESC. Eur Heart J. 2021; 42(5): 373-498, doi: 10.1093/eurheartj/ehaa612, indexed in Pubmed: 32860505.

10. Granada J, Uribe W, Chyou PH, et al. Incidence and predictors of atrial flutter in the general population. J Am Coll Cardiol. 2000; 36(7): 2242-2246, doi: 10.1016/s0735-1097(00)00982-7.

11. Stone E, Kiat H, McLachlan CS. Atrial fibrillation in COVID-19: A review of possible mechanisms. FASEB J. 2020; 34(9): 11347-11354, doi: 10.1096/fj.202001613, indexed in Pubmed: 33078484.

12. Hu YF, Chen YJ, Lin YJ, et al. Inflammation and the pathogenesis of atrial fibrillation. Nat Rev Cardiol. 2015; 12(4): 230-243, doi: 10.1038/nrcardio.2015.2, indexed in Pubmed: 25622848.

13. Szarpak $€$, Nowak B, Kosior D, et al. Cytokines as predictors of COVID-19 severity: evidence from a meta-analysis. Pol Arch Intern Med. 2021; 131(1): 98-99, doi: 10.20452/pamw.15685, indexed in Pubmed: 33219785.

14. Inciardi RM, Adamo M, Lupi L, et al. Atrial fibrillation in the COVID-19 era: simple bystander or marker of increased risk? Eur Heart J. 2020; 41(32): 3094, doi: 10.1093/eurheartj/ehaa576, indexed in Pubmed: 32699894.

15. Sanchis-Gomar F, Perez-Quilis C, Lavie CJ. Should atrial fibrillation be considered a cardiovascular risk factor for a worse prognosis in COVID-19 patients? Eur Heart J. 2020; 41(32): 3092-3093, doi: 10.1093/eurheartj/ehaa509, indexed in Pubmed: 32688380.

16. Gawałko M, Kapłon-Cieślicka A, Hohl M, et al. COVID-19 associated atrial fibrillation: Incidence, putative mechanisms and potential clinical implications. Int J Cardiol Heart Vasc. 2020; 30: 100631, doi: 10.1016/j.ijcha.2020.100631, indexed in Pubmed: 32904969.

17. Yang H, Liang X, Xu J, et al. Meta-analysis of atrial fibrillation in patients with COVID-19. Am J Cardiol. 2021; 144: 152-156, doi: 10.1016/j.amjcard.2021.01.010, indexed in Pubmed: 33508269.

18. Page MJ, McKenzie JE, Bossuyt PM, et al. The PRISMA 2020 statement: An updated guideline for reporting systematic reviews. J Clin Epidemiol. 2021; 134: 178-189, doi: 10.1016/j. jclinepi.2021.03.001, indexed in Pubmed: 33789819.

19. Sterne JAc, Hernán MA, Reeves BC, et al. ROBINS-I: a tool for assessing risk of bias in non-randomised studies of interventions. BMJ. 2016; 355: i4919, doi: 10.1136/bmj.i4919, indexed in Pubmed: 27733354.

20. McGuinness LA, Higgins JPT. Risk-of-bias VISualization (robvis): An R package and Shiny web app for visualizing risk-ofbias assessments. Res Synth Methods. 2021; 12(1): 55-61, doi: 10.1002/jrsm.1411, indexed in Pubmed: 32336025.

21. Hozo SP, Djulbegovic B, Hozo I. Estimating the mean and variance from the median, range, and the size of a sample. BMC Med Res Methodol. 2005; 5: 13, doi: 10.1186/1471-2288-5-13, indexed in Pubmed: 15840177.

22. Ades AE, Lu G, Higgins JPT. The interpretation of randomeffects meta-analysis in decision models. Med Decis Making. 2005; 25(6): 646-654, doi: 10.1177/0272989X05282643, indexed in Pubmed: 16282215.

23. Abdulrahman A, Hussain T, Nawaz S, et al. Is atrial fibrillation a risk factor for worse outcomes in severe COVID-19 patients: a single center retrospective cohort. J Saudi Heart Assoc. 2021; 33(2): 160-168, doi: 10.37616/2212-5043.1255, indexed in Pubmed: 34285872 .

24. Denegri A, Morelli M, Pezzuto G, et al. Atrial fibrillation is related to higher mortality in COVID-19/SARS-CoV-2 pneumonia infection. Cardiol J. 2021 [Epub ahead of print], doi: 10.5603/ CJ.a2021.0102, indexed in Pubmed: 34523114.

25. Ergün B, Ergan B, Sözmen MK, et al. New-onset atrial fibrillation in critically ill patients with coronavirus disease 2019 (COVID-19). J Arrhythm. 2021 [Epub ahead of print], doi: 10.1002/joa3.12619, indexed in Pubmed: 34518774.

26. García-Granja PE, Veras C, Aparisi Á, et al. Atrial fibrillation in patients with SARS-CoV-2 infection. Med Clin (Barc). 2021; 157(2): 58-63, doi: 10.1016/j.medcli.2021.01.003, indexed in Pubmed: 33637334.

27. Harrison SL, Fazio-Eynullayeva E, Lane DA, et al. Atrial fibrillation and the risk of 30-day incident thromboembolic events, and mortality in adults $\geq 50$ years with COVID-19. J Arrhythm. 2021; 37(1): 231-237, doi: 10.1002/joa3.12458, indexed in Pubmed: 33664908 .

28. Iacopino S, Placentino F, Colella J, et al. New-Onset cardiac arrhythmias during COVID-19 hospitalization. Circ Arrhythm Electrophysiol. 2020; 13(11): e009040, doi: 10.1161/CIRCEP.120.009040, indexed in Pubmed: 33021400.

29. Ip RJ, Ali A, Baloch ZQ, et al. Atrial fibrillation as a predictor of mortality in high risk COVID-19 patients: a multicentre study of 171 patients. Heart Lung Circ. 2021; 30(8): 1151-1156, doi: 10.1016/j.hlc.2021.02.010, indexed in Pubmed: 33781697.

30. Kelesoglu S, Yilmaz Y, Ozkan E, et al. New onset atrial fibrilation and risk faktors in COVID-19. J Electrocardiol. 2021; 65: 76-81, doi: 10.1016/j.jelectrocard.2020.12.005, indexed in Pubmed: 33556739 .

31. Kelesoglu S, Yilmaz Y, Ozkan E, et al. Usefulness of C-reactive protein/albumin ratio as a predictor of new-onset atrial fibrillation in SARS-COV-2. Biomark Med. 2021; 15(13): 1167-1175, doi: 10.2217/bmm-2020-0866, indexed in Pubmed: 34406031.

32. Lee JiH, Hwang YMi, Cho Y, et al. Prognostic impact of atrial fibrillation in patients with severe acute respiratory syndrome coronavirus 2 infection. Medicine (Baltimore). 2021; 100(33): e26993, doi: 10.1097/MD.0000000000026993, indexed in Pubmed: 34414982 .

33. Mountantonakis SE, Saleh M, Fishbein J, et al. Atrial fibrillation is an independent predictor for in-hospital mortality in patients admitted with SARS-CoV-2 infection. Heart Rhythm. 2021; 18(4): 501-507, doi: 10.1016/j.hrthm.2021.01.018, indexed in Pubmed: 33493650.

34. Musikantow DR, Turagam MK, Sartori S, et al. Atrial fibrillation in patients hospitalized with COVID-19: incidence, predictors, outcomes, and comparison to influenza. JACC Clin Electrophysiol. 2021; 7(9): 1120-1130, doi: 10.1016/j.jacep.2021.02.009, indexed in Pubmed: 33895107.

35. Pardo Sanz A, Salido Tahoces L, Ortega Pérez R, et al. New-onset atrial fibrillation during COVID-19 infection predicts poor prognosis. Cardiol J. 2021; 28(1): 34-40, doi: 10.5603/CJ.a2020.0145, indexed in Pubmed: 33140386.

36. Peltzer B, Manocha KK, Ying X, et al. Outcomes and mortality associated with atrial arrhythmias among patients hospitalized with COVID-19. J Cardiovasc Electrophysiol. 2020; 31(12): 3077-3085, doi: 10.1111/jce.14770, indexed in Pubmed: 33017083.

37. Rubini-Costa R, Bermúdez-Jiménez F, Rivera-López R, et al. Prevalence of bleeding secondary to anticoagulation and mortality in patients with atrial fibrillation admitted with SARS-CoV-2 infection. Med Clin (Barc). 2021 [Epub ahead of print], doi: 10.1016/j.medcli.2021.06.015, indexed in Pubmed: 34364707. 
38. Russo V, Di Maio M, Mottola FF, et al. Clinical characteristics and prognosis of hospitalized COVID-19 patients with incident sustained tachyarrhythmias: A multicenter observational study. Eur J Clin Invest. 2020; 50(12): e13387, doi: 10.1111/eci.13387, indexed in Pubmed: 32813877.

39. Slipczuk L, Castagna F, Schonberger A, et al. Incidence of newonset atrial fibrillation in COVID-19 is associated with increased epicardial adipose tissue. J Interv Card Electrophysiol. 2021 [Epub ahead of print], doi: 10.1007/s10840-021-01029-4, indexed in Pubmed: 34231098.

40. Spinoni EG, Mennuni M, Rognoni A, et al. Contribution of Atrial Fibrillation to In-Hospital Mortality in Patients With COVID-19. Circ Arrhythm Electrophysiol. 2021; 14(2): e009375, doi: 10.1161/CIRCEP.120.009375, indexed in Pubmed: 33591815.

41. Uribarri A, Núñez-Gil IJ, Aparisi Á, et al. HOPE COVID-19 investigators. Atrial fibrillation in patients with COVID-19. Usefulness of the CHADS-VASc score: an analysis of the international HOPE COVID-19 registry. Rev Esp Cardiol (Engl Ed). 2021; 74(7): 608-615, doi: 10.1016/j.rec.2020.12.009, indexed in Pubmed: 33583755 .

42. Taha ME, Alsafi W, Taha M, et al. Coronavirus disease and newonset atrial fibrillation: two cases. Cureus. 2020; 12(5): e8066, doi: 10.7759/cureus.8066, indexed in Pubmed: 32542123.

43. Sala S, Peretto G, De Luca G, et al. Low prevalence of arrhythmias in clinically stable COVID-19 patients. Pacing Clin Electrophysiol. 2020; 43(8): 891-893, doi: 10.1111/pace.13987, indexed in Pubmed: 32543745.

44. Seecheran R, Narayansingh R, Giddings $S$, et al. Atrial arrhythmias in a patient presenting with coronavirus disease-2019 (COVID-19) infection. J Investig Med High Impact Case Rep. 2020; 8: 2324709620925571, doi: 10.1177/2324709620925571, indexed in Pubmed: 32370558.

45. Kochav SM, Coromilas E, Nalbandian A, et al. Cardiac arrhythmias in COVID-19 infection. Circ Arrhythm Electrophysiol. 2020; 13(6): e008719, doi: 10.1161/CIRCEP.120.008719, indexed in Pubmed: 32434385.

46. Tomasoni D, Italia L, Adamo M, et al. COVID-19 and heart failure: from infection to inflammation and angiotensin II stimulation. Searching for evidence from a new disease. Eur J Heart Fail. 2020; 22(6): 957-966, doi: 10.1002/ejhf.1871, indexed in Pubmed: 32412156.

47. Chen L, Li X, Chen M, et al. The ACE2 expression in human heart indicates new potential mechanism of heart injury among patients infected with SARS-CoV-2. Cardiovasc Res.
2020; 116(6): 1097-1100, doi: 10.1093/cvr/cvaa078, indexed in Pubmed: 32227090.

48. Murray IR, Baily JE, Chen WCW, et al. Skeletal and cardiac muscle pericytes: Functions and therapeutic potential. Pharmacol Ther. 2017; 171: 65-74, doi: 10.1016/j.pharmthera.2016.09.005, indexed in Pubmed: 27595928.

49. Avolio E, Madeddu P. Discovering cardiac pericyte biology: From physiopathological mechanisms to potential therapeutic applications in ischemic heart disease. Vascul Pharmacol. 2016; 86: 53-63, doi: 10.1016/j.vph.2016.05.009, indexed in Pubmed: 27268036.

50. Marcus GM, Whooley MA, Glidden DV, et al. Interleukin-6 and atrial fibrillation in patients with coronary artery disease: data from the Heart and Soul Study. Am Heart J. 2008; 155(2): 303-309, doi: 10.1016/j.ahj.2007.09.006, indexed in Pubmed: 18215601.

51. Amdur RL, Mukherjee M, Go A, et al. Interleukin-6 Is a Risk Factor for Atrial Fibrillation in Chronic Kidney Disease: Findings from the CRIC Study. PLoS One. 2016; 11(2): e0148189, doi: 10.1371/journal.pone.0148189, indexed in Pubmed: 26840403.

52. Ren M, Li X, Hao Li, et al. Role of tumor necrosis factor alpha in the pathogenesis of atrial fibrillation: A novel potential therapeutic target? Ann Med. 2015; 47(4): 316-324, doi: 10.3109/07853890.2015.1042030, indexed in Pubmed: 25982799.

53. Guo Y, Lip GYH, Apostolakis S. Inflammation in atrial fibrillation. J Am Coll Cardiol. 2012; 60(22): 2263-2270, doi: 10.1016/j. jacc.2012.04.063, indexed in Pubmed: 23194937.

54. Savelieva I, Kakouros N, Kourliouros A, et al. Upstream therapies for management of atrial fibrillation: review of clinical evidence and implications for European Society of Cardiology guidelines. Part II: secondary prevention. Europace. 2011; 13(5): 610-625, doi: 10.1093/europace/eur023, indexed in Pubmed: 21515595.

55. Wanamaker B, Cascino T, McLaughlin V, et al. Atrial arrhythmias in pulmonary hypertension: pathogenesis, prognosis and management. Arrhythm Electrophysiol Rev. 2018; 7(1): 43-48, doi: 10.15420/aer.2018.3.2, indexed in Pubmed: 29636972.

56. Shahreyar M, Fahhoum R, Akinseye O, et al. Severe sepsis and cardiac arrhythmias. Ann Transl Med. 2018; 6(1): 6, doi: 10.21037/atm.2017.12.26, indexed in Pubmed: 29404352.

57. Christian SA, Schorr C, Ferchau L, et al. Clinical characteristics and outcomes of septic patients with new-onset atrial fibrillation. J Crit Care. 2008; 23(4): 532-536, doi: 10.1016/j.jcrc.2007.09.005, indexed in Pubmed: 19056018. 